\title{
Additional Evidence on the Influence of Light in producing Pigments on the Lower Sides of Flat Fishes.
}

By

\author{
J. T. Cunningham, M.A.
}

\section{An Observation on Plaice and Flounders.}

IN a communication to the Royal Society (Phil. Trans. vol, clxxxiv. 1894, and in this Journal, vol. ii. no. 1), I described a series of experiments in which light was directed upon the lower sides of flat fishes, by means of a tank with a glass bottom, and a mirror placed beneath it. I have now to record an observation which confirms my previous results in a most striking manner. Curiously enough, the effect I am about to describe, in some respects even more important as evidence than those obtained in my experiments, was observed accidentally, or at least incidentally, and was due to conditions which had been quite unintentionally produced.

On December 31st, 1894, I examined all the flat fishes which had been kept in a certain tank, for the purpose of ascertaining their rate of growth. These fishes were five in number, namely :

$$
\begin{aligned}
& 1 \text { plaice . } 8 \frac{1}{4} \text { in. long. } 1 \text { flounder . } 6 \frac{7}{8} \text { in. long } \\
& 1 \text {. } 7 \frac{1}{4}, 1 \text {. } 1 \frac{5}{8} \text { " } \\
& 1 \text { sole . } 5 \frac{3}{4} \text { in. long. }
\end{aligned}
$$

There were no other flat fishes in the tank, which was one of the table-tanks in the Laboratory of the Association, at Plymouth. It was $5 \mathrm{ft}$. long, $2 \mathrm{ft} .6 \mathrm{in}$. wide and $15 \mathrm{in}$. deep, and its sides and bottom were of slate, the front of glass. I was surprised to notice that all these flat fishes were partially pigmented on their lower sides. At first this appeared to be a complete nullification of the conclusions drawn from my previous experiments, but further examination of the matter gave it a different interpretation. 
In the sole there was very little pigmentation on the lower side, only a little at the base of the tail, and on the lower surface of the tail, but in the plaice and flounders the pigmentation extended continuously over the marginal region of the body and the proximal part of the dorsal and ventral fins. The extent of the pigment in the smaller flounder is shown in Fig. 1. The pigmentation of the outer half of the marginal fins was slight. In the larger flounder the pigmented area on the surface of the body was broader; the central area was unpigmented, with the exception of a narrow patch about the middle of the lateral line, as in the smaller specimen. In the two plaice the pigmentation was not quite so intense and not quite so extensive. In both it was absent, or very nearly so, from the surface of the marginal fins, and from the anterior part of the body, with the exception of a small

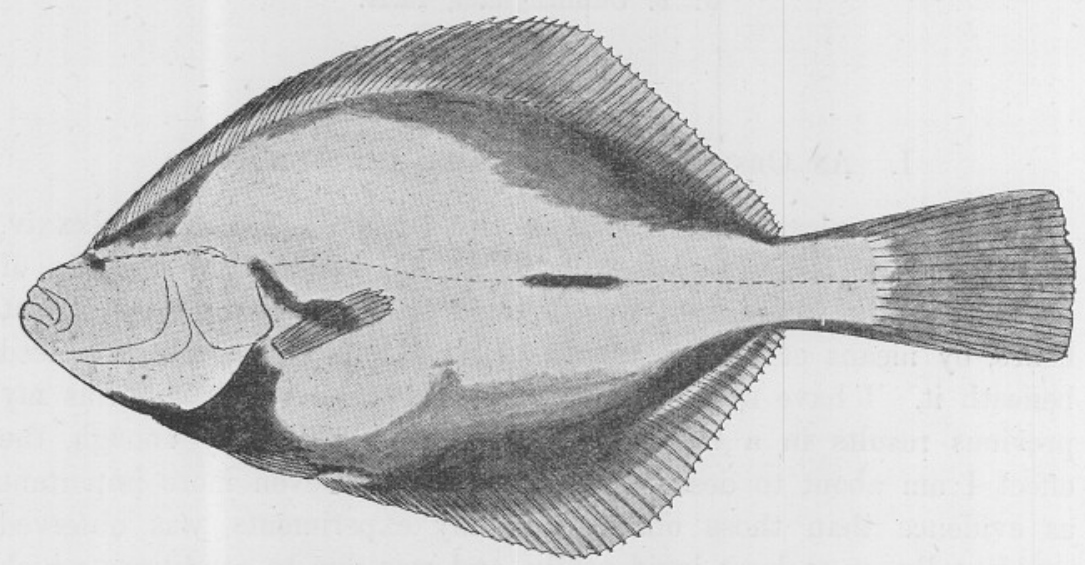

FIG. 1.-Under side of Flounder, showing pigmentation.

patch on the bony ridge of the head in the smaller specimen. In both it was present in the regions of the interspinous bones in the posterior three-fourths of the body, both dorsally and ventrally, and also over the whole lower surface of the caudal fin, absent from the central region of the body entirely; there was no patch on the lateral line, as in the flounders.

It will be clear, therefore, that there was a most remarkable similarity in the distribution of the pigment in these four specimens, which suggests a common cause acting in all of them, and not indefinite "variation." This common cause was access of light to the pigmented areas. There was no sand or gravel at the bottom of the tank, and the fish were resting on the bare slate. The lower surfaces of the fish were not perfectly flat, and therefore certain areas were, when the fish were at rest, in contact with the slate, while other areas were separated from 
the slate by an interval. The areas of contact were shown by dropping the smaller flounder, in the moist fresh state, on a surface of dry slate, when the areas in contact moistened the slate, while the part of the slate not touched by the fish remained dry.

Fig. 2 is a diagram of the impression thus produced on the slate by the fish, and it will be seen that it is a remarkably exact negative of the distribution of the pigment on the lower surface of the fish. The projection of the area of contact towards the dorsal edge of the fish is not so extensive as the unpigmented area on the dorsal region of the body of the fish, and the tail is in contact with the slate. But in view of the exact correspondence in other respects, these differences are easily explained, and do not invalidate the evidence. The white patch

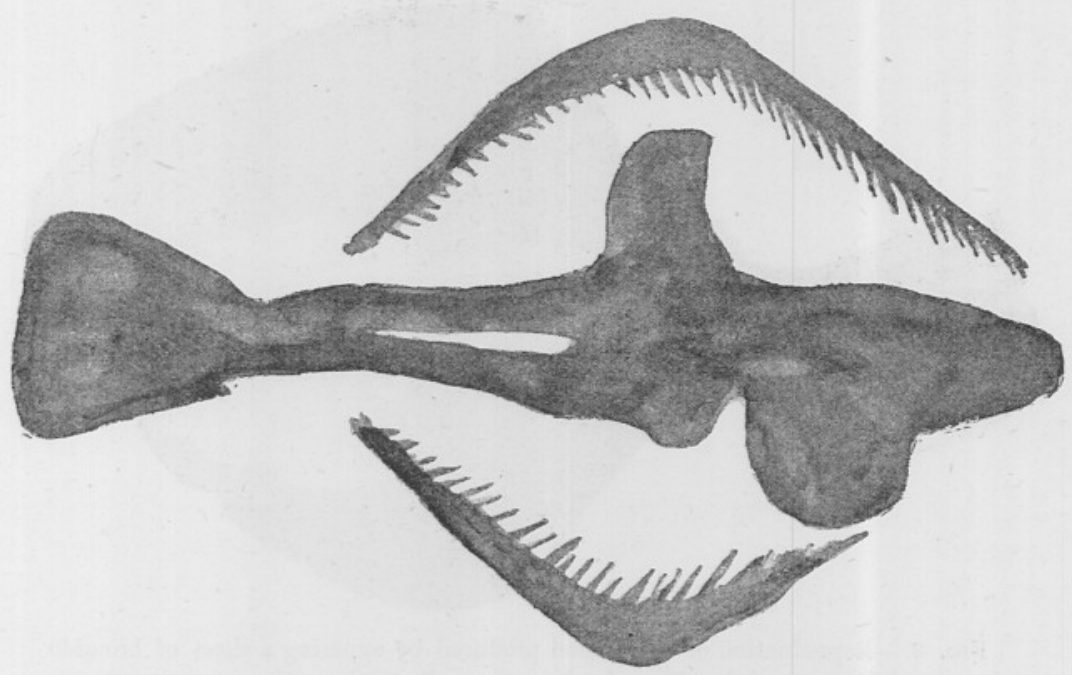

Fig. 2.-Impression of under side of Flounder on dry slate.

in Fig. 2, corresponding to the area of pigment on the lateral line, and the remarkable correspondence of the area of contact ventrally with the outline of the pigmented area in the fish, as shown in Fig. 2, are sufficiently striking. With regard to the isolated patch of pigment on the lateral line, a difficulty arises. Since this small area is an island surrounded everywhere by surfaces in contact with the bottom, how could light reach it?

In order to prove that light does reach the pigmented areas, I had recourse to photographic action. The same flounder was placed, while still alive, on a sheet of bromide printing-paper in the dark room, and then exposed for a few seconds to daylight, to light coming horizontally. The result of one such experiment is shown in Fig. 3. Here, again, 
the darkened area of the paper corresponds with remarkable exactness to the pigmented area of the fish, and, most remarkable of all, there is a small darkened patch corresponding to the isolated pigmented patch on the lateral line of the fish. In this particular photographic print the outer region of the bromide paper, beyond the edges of the fish, is lighter than the outer part of the area covered by the fish. This is simply due to the over-exposure of the uncovered area of the paper, causing a partial reversal of the photographic effect. It must be concluded that the rays of light which reach the small depression on the lateral line of the fish pass parallel to the surface of the fish, and therefore do not fall upon it; but when they reach the edges of the depression they are slightly refracted, and so

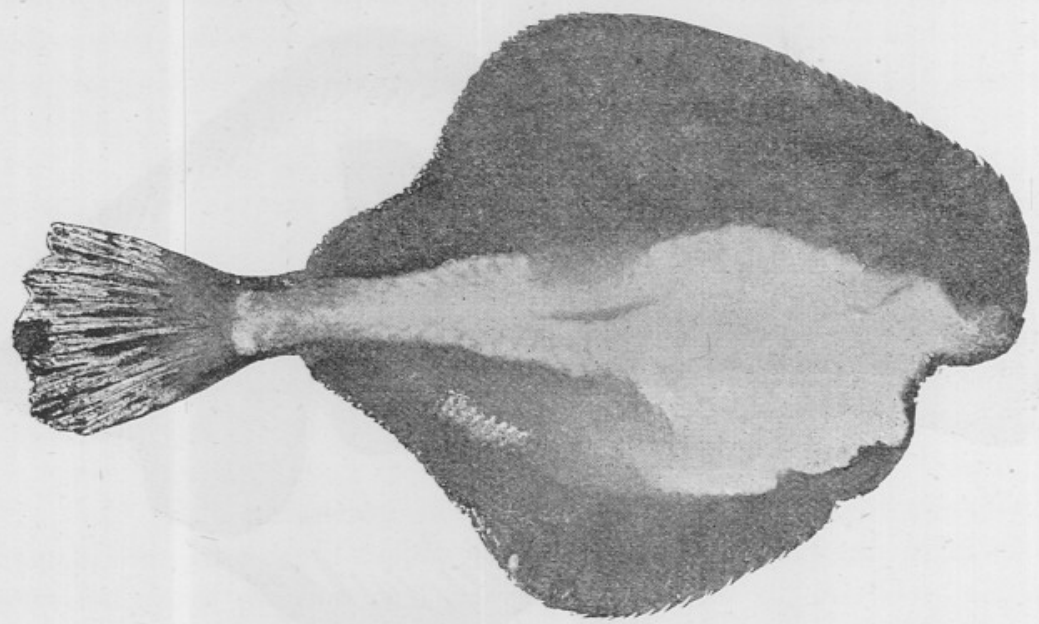

FIG. 3. - Reproduction of impression produced by exposing a sheet of bromide photographic paper, with a Flounder lying upon it, to the action of diffuse light, and subsequently developing.

fall upon the surface of the skin in the depression, and give rise to pigmentation. It is possible that this explanation may be corrected by physicists, who know more of the properties of light-rays than I do; but the proof in the photograph that light does reach the depression, and produce an effect there which is absent from the surrounding area, is quite sufficient for my argument.

It will probably be admitted that what applies to one of the fish applies to all. In any case, sufficient examination was made to show that the differences in the amount of pigmentation corresponded to differences in the shape of the lower surfaces of the fish. The lower side of the sole was flat, and in contact everywhere except at the base of the tail. When the fish were alive their caudal fins were usually 
held slightly elevated above the slate bottom, which accounts for the pigmentation of the lower side of that fin.

It is now necessary to give the history of these fish. (See the previous number of this Journal, vol. iii. p. 273.) They were the survivors of a number put into the tank in the summer of the year 1893, and judged to be hatched in the early part of that year. In April and May were put in five soles, about $1.5 \mathrm{~cm}$. long, and a few flounders from 1.0 to $1.5 \mathrm{~cm}$. long. In June a few young turbot and brill, in the pelagic transformation stages, were put in. In July there were added seven plaice, 6.5 to $8.5 \mathrm{~cm}$. long, and judged to have been hatched the preceding January. On October 19th there were found to be in the tank seven plaice, one sole, three brill, three turbot, and several flounders, but no note was made of the presence or absence of pigment on the lower side. The fish were simply reared in order to see their growth, and it was not supposed that any conditions affecting pigmentation were present. On April 4th, 1894, some of the fish died, and the notes of their condition taken at the time are as follows:

One turbot $10.8 \mathrm{~cm}$. long, a little pigment on the lower side, on the marginal fins, and within their bases.

One brill $11.3 \mathrm{~cm}$. long, pigment on lower side near bases of marginal fins.

One plaice $16.7 \mathrm{~cm}$. long, no pigment on lower side.

One flounder $12 \mathrm{~cm}$. long, some pigment on lower side near bases of fins.

One flounder $11 \mathrm{~cm}$. long, no pigment on lower side.

Thus, in three out of five of these specimens there was some pigment on the lower side in the same region as in the fishes above described from the same tank. But at this time I did not pay much attention to it, and thought it was only an instance of casual variation.

The five fish first described had thus been living in the tank about a year and a half. The tank having a glass front, and being at a height of about 5 feet from the ground, opposite a north window, many of the rays of light entering it must have been nearly horizontal. The glass front, however, did not extend quite to the bottom of the tank, the lower 4 inches of the front being formed of slate. Although it is difficult to make an exact comparison, it certainly seems that the pigmentation was produced more constantly and more rapidly in the unintentional experiment here described, than in those recorded in the previous memoir, which I took so much trouble to arrange. Thus the survivors of the specimens of the brood of 1892 , reared in the glass-bottom tank, died on October 20th, 1893, and had therefore been exposed to light very nearly as long as the five described in this paper. They were ten in number, and four of them had no pigment at all on 
the lower sides. It cannot well be suggested, in explanation of this, that light is not the cause of the pigmentation, but simply the absence of mechanical contact over the parts of the skin which did not touch the bottom in the slate tank. For, in the first place, the same reason would apply to the fish in the glass-bottom tank, where there was no sand, and the marginal parts of the body were equally separated from the bottom; and, in the second place, in the experiments with the glass-bottom tank and mirror, the pigment when developed was most abundant, precisely in those more central regions of the body which were in contact with the glass bottom. I can only suggest at present, that light reflected from rather dark coloured surroundings, is more efficient in producing the pigment than that coming directly from a window and reflected by a silvered mirror. Mr. Poulton has shown how remarkably the colour of lepidopterous pupæ is affected by the colour of the surroundings to which the caterpillars are exposed during pupation.

\section{An Experiment on a Piebald Plaice.}

In the previous number (p. 271) I described a piebald specimen of the plaice, and suggested the possibility that if the lower side were exposed to light the unpigmented area on the upper side would, pari passu, become pigmented. This result was the logical consequence of the hypothesis I put forward in explanation of the fact that, in such specimens, part of the upper side remains unpigmented, while continuously exposed to light in the same way as normal specimens. After writing the contribution to which I refer, I instituted the experiment with the same specimen, not, I must confess, with very sanguine hopes of its success. The specimen had lived in the aquarium from October 3rd to the month of December, without showing any change in pigmentation. I then placed it in a large bell-jar, without any sand, gravel, or other objects in the water, and placed the jar over a mirror in front of a south window. The top and front of the jar were shaded with black paper, so that the upper side received little light, the lower side a great deal. I left the Laboratory on February $2 \mathrm{nd}$, in order to take charge of the east coast work at Grimsby, and Mr. Allen, the new Director of the Laboratory, kindly consented to take this and other experiments of mine under his care. I am most grateful to him for the fidelity with which he executed this trust. When I returned to Plymouth, on June 17th, I found the plaice still alive and in good health. The fish, on examination, was found to be 7 inches long. On the lower side, where previously there was no trace of pigment, there were numerous small patches; scattered principally, 
but not exclusively, over the peripheral, or interspinous regions. In the area of the upper side, which was previously unpigmented, there were numerous small pigment spots. It is true that the amount of pigmentation thus produced was not great, but it was perfectly distinct and evident, and the duration of the experiment was less than six months. It will easily be seen that this is a most remarkable resultthe most remarkable of all that I have obtained in the course of these researches. It is not often in biological investigation that the result of an experiment so exactly corresponds to the prediction, and it affords very strong evidence that the view I advocated of the meaning of the occurrence of unpigmented areas on the upper sides of flatfishes, approximates closely to the truth. It may be objected that possibly the formation of pigment would have occurred equally if the lower side had not been exposed to light, and it would be desirable to keep other piebald specimens for a length of time under normal conditions. But it can scarcely be maintained that the unpigmented area, when the fish was free, had been shielded from light, and that pigment would have been produced in the aquarium merely in consequence of the exposure of the upper side alone. We have no facts to indicate that the peculiar distribution of pigment in these specimens undergoes changes in the lifetime of the individual, in a state of nature, or in the aquarium, under ordinary conditions. We can only hold, at present, that the pigmentation is constant for the individual, under the usual conditions, although in the face of the result here recorded, it will be advisable to test this assumption. I hope, at some future time, to publish figures shewing the specimen before and after the experiment; but in the mean time have thought it well to place the result on record. 


\title{
The Reproduction of the Lobster.
}

\author{
By
}

E. J. Allen, B.Sc.

Director of the Plymouth Laboratory.

The Habits and Developinent of the Lobster, and their bearing upon its Artificial Propagation. By Francis H. Herrick, Professor of Biology in Adelbert College. Bulletin of the United States Fish Commission, vol, xiii. 1893.

The Reproduction of the Lobster. By Francis H. Herrick. Zoologischer Anzeiger, xvii. August, 1894, and xviii. June, 1895.

Lobster Reproduction. By S. Garman, Mus. Comp. Zool. Cambridge, Mass. U.S.A. Zoologischer Anzeiger, xviii. Feb. 1895.

Der Helgolander Hummer ein Gegenstand deutscher Fischerei, von Dr. Ernst Ehrenbaum. Wissenschaftliche Meeresuntersuchungen herausgegeben von der Komm. z. wiss. Untersuch d. deutschen Meere in Kiel u.d. Biol. Aust. auf Helgoland, Neue Folge, heft i. 1894.

Amongst the numerous subjects which have occupied the attention of the fishery authorities of the United States, that of the great decline in the productiveness of the lobster fishing industry has received much consideration, and several competent naturalists have, in consequence, devoted themselves to a scientific study of the habits and life-history of the American species. This species (Homarus Americanus) is so nearly allied to the European lobster (Homarus vulgaris), that the results arrived at for it, with regard to such questions as the time of year at which spawning takes place, the length of time during which the eggs are carried by the female attached to the under side of the abdomen, and the time of year at which the eggs are hatched, might be expected to apply, to some extent at least, to the latter. That this is so, appears to be abundantly proved by Dr. Ehrenbaum's study of the lobsters which frequent the shores of Heligoland, and certain observations which I have been able to make on lobsters taken in the neighbourhood of Plymouth during the last two years, in the course of my work on the nervous system of the embryo, also tend to confirm this view.

In America, the investigation of the subject seems to have been carried on independently, at about the same time, by Herrick and 
Bumpus, working at the U.S. Fish Commission Station, at Woods Holl, Mass., and by Garman, in connection with the State Fish Commission, of Massachusetts. It would appear that Herrick's work was commenced during the season of 1889 , his most important results being published in May, 1891,* whilst Garman turned his attention to the subject in 1890, and reported his conclusions to the Massachusetts State Fish Commission, in December, 1891. On most points of importance, the independent researches of these different investigators are so much in accord, that there can be little doubt as to their correctness.

The time of year during which eggs are laid by the American lobster appears, from Herrick's recent papers $\dagger$ to be less restricted than had previously been supposed. As the result of his earlier work, he was of opinion that the period of egg-laying was confined to the summer months, and that the eggs were carried by the female until the summer following, when they were hatched. A similar view is also taken by Garman. This statement of the facts, however, Herrick now regards as only partially true, for, whilst the greater number of females deposit their eggs during the months of June, July, and August, a considerable number-probably, at least, ten per cent.-lay eggs during the autumn, winter, and spring months. ${ }_{+}^{+}$

For eggs laid during the summer, Herrick, Bumpus, and Garman agree as to the time occupied in development. They are carried by the female from ten to eleven months before being hatched, this event taking place, in the majority of cases, during June and July of the year following that in which they are laid. During the first few weeks development proceeds rapidly, the eyes being already visible after a month from the time of laying. As the colder weather comes on the process is much retarded, and advance is slow during the winter. According to Herrick, however, the period of fosterage varies considerably in eggs not produced in the summer, some of which may hatch in the fall, and possibly in the winter months.

On these points Ehrenbaum is able to give valuable information concerning the Heligoland lobsters. Special opportunities for the study of the subject are afforded at this place, as the fishermen and dealers keep great numbers of lobsters in large, floating cages for considerable periods, especially in summer. In these cages, however, the females do not, in the majority of cases, deposit their spawn, probably on account of their being shut up in a confined space with a number of their

* Johns Hopkins Univ. Circulars, vol. x. no. 87, and Zool. Anzeiger, nos. 361 and 362 .

+ Zool. Anzeiger, August, 1894, and June, 1895.

¥ Nielsen states that, in Newfoundland, the larger lobsters spawn from the middle of June till the middle of August, whilst the smaller do not lay until the latter part of October and November. (Annual Report, Newfoundland Fisheries Commission, 1889, p. 12.) 